\title{
In vivo and in vitro assessment of pathways involved in contrast media-induced renal cells apoptosis
}

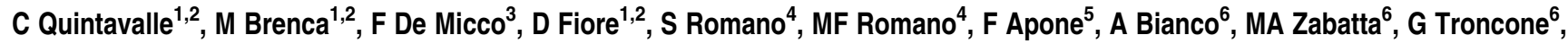 \\ C Briguori ${ }^{*, 3}$ and G Condorelli, ${ }^{*}, 2$
}

Contrast-induced nephropathy accounts for $>10 \%$ of all causes of hospital-acquired renal failure, causes a prolonged inhospital stay and represents a powerful predictor of poor early and late outcome. Mechanisms of contrast-induced nephropathy are not completely understood. In vitro data suggests that contrast media (CM) induces a direct toxic effect on renal tubular cells through the activation of the intrinsic apoptotic pathway. It is unclear whether this effect has a role in the clinical setting. In this work, we evaluated the effects of $\mathrm{CM}$ both in vivo and in vitro. By analyzing urine samples obtained from patients who experienced contrast-induced acute kidney injury (Cl-AKI), we verified, by western blot and immunohistochemistry, that $\mathrm{CM}$ induces tubular renal cells apoptosis. Furthermore, in cultured cells, CM caused a dose-response increase in reactive oxygen species (ROS) production, which triggered Jun N-terminal kinases (JNK1/2) and p38 stress kinases marked activation and thus apoptosis. Inhibition of JNK1/2 and p38 by different approaches (i.e. pharmacological antagonists and transfection of kinasedeath mutants of the upstream p38 and JNK kinases) prevented CM-induced apoptosis. Interestingly, $\mathrm{N}$-acetylcysteine inhibited ROS production, and thus stress kinases and apoptosis activation. Therefore, we conclude that CM-induced tubular renal cells apoptosis represents a key mechanism of Cl-AKI.

Cell Death and Disease (2011) 2, e155; doi:10.1038/cddis.2011.38; published online 12 May 2011

Subject Category: Experimental Medicine

Acute kidney injury (AKI) represents a frequent and devastating problem in hospitalized adults with persistently high rates of mortality and morbidity. Studies of large adult cohorts have revealed that contrast-induced $\mathrm{AKI}(\mathrm{Cl}-\mathrm{AKI})$ is the third most common cause of hospital-acquired $\mathrm{AKI}$, accounting for $>10 \%$ of cases. Approximately half of these cases are of patients undergoing contrast media (CM) exposure because of the cardiac catheterization and angiography, and about one-third follow computed tomography. A clear comprehension of the mechanisms of $\mathrm{Cl}-\mathrm{AKI}$ may, therefore, have important clinical advantages. A toxic effect of $\mathrm{CM}$ on renal tubules has been shown in both clinical trials and animal experiments. ${ }^{1-3}$ In an experimental study, we previously observed that CM induces a dose- and time-dependent renal cell apoptosis through the activation of the intrinsic pathway. ${ }^{4}$ However, it is unclear whether this effect has a role in the clinical setting. Furthermore, little is known about the molecular mechanisms underlying this contrast-induced renal cell apoptosis.

Apoptosis is an evolutionarily conserved mechanism of elimination of the unwanted cells. ${ }^{5}$ The extrinsic pathway is activated by the engagement of death receptors on the cell surface. The intrinsic pathway is triggered by various intracellular and extracellular stresses whose signals converge mainly to the mitochondria. ${ }^{6,7}$ Studies in humans indicate that reactive oxygen species (ROS) contribute to contrast-induced acute kidney injury (Cl-AKI). ${ }^{8-10}$ Indeed, several animal experiments showed that $\mathrm{Cl}-\mathrm{AKI}$ is accompanied by the increased production of ROS. ${ }^{11,12}$ ROS activate stress kinases, ${ }^{13,14}$ such as the mitogen-activated protein kinases (MAPKs). ${ }^{15}$ MAPKs include at least three main subgroups: the extracellular signal-regulated kinases (ERK1/2 or p42/44MAPK), the c-Jun N-terminal kinases (JNK 1/2), and p38MAPK. Although structurally related MAPK families undergo activation in response to extracellular stimuli through distinct upstream dual specificity kinases, thereby functioning in separate MAPK cascades. $^{16}$ The Raf/ERK kinase1/2/ERK1/2 cascade is stimulated by mitogenic and survival stimuli, largely through the Ras-Raf-1-dependent pathway. ${ }^{17}$ At variance, JNK1/2 and p38MAPK are primarily activated by cellular stresses, including oxidative agents, UV

\footnotetext{
${ }^{1}$ Department of Cellular and Molecular Biology and Pathology, 'Federico II' University of Naples, Naples, Italy; ${ }^{2}$ IEOS, CNR Naples, Naples, Italy; ${ }^{3}$ Laboratory of Interventional Cardiology and Department of Cardiology, Clinica Mediterranea, Naples, Italy; ${ }^{4}$ Department of Biochemistry and Medical Biotechnology, Federico II University of Naples, Naples, Italy; ${ }^{5}$ Arterra Bioscience, Naples, Italy and ${ }^{6}$ Dipartimento di Scienze Biomorfologiche e Funzionali, Università di Napoli Federico II, Naples, Italy

${ }^{*}$ Corresponding authors: C Briguori, Laboratory of Interventional Cardiology and Department of Cardiology, Clinica Mediterranea, Via Orazio, 2, Naples I-80121, Italy. Tel: + 390817259 764; Fax: + 390817259 777; E-mail: carlobriguori@clinicamediterranea.it

or G Condorelli, Department of Cellular and Molecular Biology and Pathology, 'Federico II' University of Naples, Via Pansini, 5, Naples I-80121, Italy and IEOS, CNR Naples, Naples, Italy.

Tel: + 39081746 4416; Fax: + 39081746 3308; E-mail: gecondor@unina.it

Keywords: contrast media; kidney; apoptosis; prevention

Abbreviations: $\mathrm{CM}$, contrast media; Cl-AKI, contrast-induced acute kidney injury; ROS, reactive oxygen species; JNK 1/2, Jun N-terminal kinases 1 e 2; NAC, $\mathrm{N}$-acetylcysteine; AKI, acute kidney injury; MAPK, mitogen-activated protein kinases; ERK, extracellular signal-regulated kinases; MKK, MAP kinase kinases; Gal-3, galactine-3; CK7, cytokeratin 7; LOCM, low-osmolar contrast media; IOCM, iso-osmolar contrast media; PKC, protein kinase C; SAPK, stress-activated protein kinase; Bcl-2, B-cell lymphoma 2; MDCK, Madin-Darby canine kidney; CKD, chronic kidney disease; EGTA, ethylene glycol tetraacetic acid; PBS, phosphate-buffered saline Received 15.2.11; revised 09.3.11; accepted 23.3.11; Edited by V De Laurenzi
} 
irradiation, hypoxia, and proinflamatory cytokines. ${ }^{18}$ Dual specificity kinases activating JNK are MAP kinase kinases (MKK) 4 and MKK7, whereas MKK3 and MKK6 were proved to activate p38MAPK.

In this study, we investigated (1) the in vivo occurrence of $\mathrm{CM}$-induced tubular renal cells apoptosis; (2) the in vitro and in vivo effects of $\mathrm{CM}$ on stress kinases and apoptotic pathways; (3) the in vitro effects $\mathrm{CM}$ on ROS production in renal tubular cells; and (4) the in vitro effects of stress kinases inhibition by different approaches in preventing the contrastinduced cell damage.

\section{Results}

In vivo assessment of the apoptotic pathway. The characteristics of the 10 patients enrolled in this study are summarized in Table 1. Epithelial tubular cells were observed in all cases at both 24 and $48 \mathrm{~h}$ following $\mathrm{CM}$ exposure. Tubular cells occurred in clusters and casts, and showed clear or vacuolated cytoplasm, intracytoplasmic pigmented granules, and nuclear changes. The presence of epithelial tubular cells was confirmed by both morphological and immunocytochemical criteria. The former were evaluated on cytospin preparations stained by standard Papanicolaou or hematoxylin-eosin staining method (Figures $1 \mathrm{a}$ and $\mathrm{b}$ ); the latter were assessed by immunostaining for the galactine-3 (Gal-3; Figure 1c) and cytokeratin 7 (CK7) tubular cell markers (Figure 1d). In all these patients, we observed in vivo, the activation of the apoptotic process by the assessment of caspase 3 activation was analyzed either by immunocytochemistry (Figures $1 e$ and f) or by western blot (Figure 2c).

CM and stress kinases. We then evaluated the activation of JNK1/2 (with the use of specific antibodies that recognize the phosphorylated (activated) form of the kinases), and the expression of the anti-apoptotic protein BAK in epithelial tubular cells collected from these patients. In all these patients, we observed a significantly increase of JNK phosphorylation (Figure 2a) and an increase of BAK expression levels (Figure 2b).

In the in vitro model, all tested $\mathrm{CM}$ induced a dosedependent phosphorylation of JNK1/2 and p38. Indeed, although at low level, this activation was observed even with low dose $(50 \mathrm{mgl} / \mathrm{ml})$ of $\mathrm{CM}$ (Figure 3$)$. Furthermore, this effect was time-dependent and reached the maximum level at $1 \mathrm{~h}$. $\mathrm{N}$-acetylcysteine (NAC) pre-incubation induced a significant reduction of phosphorylation levels of JNK1/2 (Figures $4 a-c$ ). Moreover, this effect was associated with a reduction of caspase 3 activation, as assessed by caspase 3 assay (Figure 4d). CM also induced an increase in the expression levels of the B-cell lymphoma $2(\mathrm{Bcl} 2)$ family pro-apoptotic proteins, namely, BAX, BAK, and BAD. Interestingly, the pre-treatment with JNK $1 / 2$ inhibitor prevented this effect (Figure 5).

Pre-treatment with stress kinases inhibitors decreases apoptosis. To establish a more direct link of JNK 1/2 and p38 with CM-induced apoptosis, we used two different
Table 1 Clinical characteristics

\begin{tabular}{|c|c|}
\hline & $N=10$ \\
\hline $\begin{array}{l}\text { Age (years) } \\
\text { Male (\%) } \\
\text { Weight }(\mathrm{kg}) \\
\text { Height }(\mathrm{m}) \\
\text { Body mass index }\left(\mathrm{kg} / \mathrm{m}^{2}\right)\end{array}$ & $\begin{array}{c}70 \pm 9(41-90) \\
9(90) \\
76 \pm 12 \\
1.68 \pm 0.6 \\
27 \pm 3\end{array}$ \\
\hline $\begin{array}{l}\text { Blood pressure }(\mathrm{mm} \mathrm{Hg}) \\
\text { Systolic } \\
\text { Diastolic } \\
\text { Mean }\end{array}$ & $\begin{aligned} 150 & \pm 19 \\
80 & \pm 8 \\
102 & \pm 10\end{aligned}$ \\
\hline $\begin{array}{l}\text { Left ventricular ejection fraction (\%) } \\
\text { Systemic hypertension (\%) } \\
\text { Diabetes mellitus (\%) }\end{array}$ & $\begin{array}{l}50 \pm 10 \\
8(80) \\
4(40)\end{array}$ \\
\hline $\begin{array}{l}\text { Serum creatinine, median (IQR; } \mathrm{mg} / \mathrm{dl}) \\
\text { Baseline } \\
\text { After } 24 \mathrm{~h} \\
\text { After } 48 \mathrm{~h}\end{array}$ & $\begin{array}{l}1.64(1.51-1.90) \\
1.70(1.50-1.99) \\
2.01(1.85-6.89)\end{array}$ \\
\hline eGFR $\left(\mathrm{ml} / \mathrm{min}\right.$ per $\left.1.73 \mathrm{~m}^{2}\right)$ & 4110 \\
\hline $\begin{array}{l}\text { Performed procedure } \\
\text { Coronary angiography (\%) } \\
\mathrm{PCl}(\%) \\
\text { Coronary angiography and ad hoc } \mathrm{PCl}(\%)\end{array}$ & $\begin{array}{l}4(40) \\
2(20) \\
4(40)\end{array}$ \\
\hline Volume of contrast media (ml) & $165 \pm 125$ \\
\hline
\end{tabular}

Abbreviations: eGFR, estimated glomerular filtration rate; IQR, interquartile range; $\mathrm{PCl}$, percutaneous coronary intervention. Continuous values are expressed ad mean \pm S.D.; categorical values are expressed as a total number and as a percentage of the global population (in parenthesis)

approaches. First, we investigated the effect of specific stress kinase inhibitors. Pre-treatment of renal cells with two different JNK 1/2 inhibitors (SP600125 and AS601245; Figure 6) and with a p38 inhibitor (SB203380; Figure 7a) strongly attenuated $\mathrm{CM}$-induced renal cell apoptosis. On the contrary, inhibitors toward other kinases, such as ERK and protein kinase $\mathrm{C}(\mathrm{PKC})$, did not impact on CM-induced apoptosis (Figures 7c and d). Second, we thought to transfect the cells with kinase-death mutants of the upstream p38 and JNK1/2 kinases, MKK6-KR, and MKK4$K R$, respectively. As shown in Figure $7 b$, the kinase-death mutants attenuated the CM-induced cell death. This effect was even stronger on co-transfection of both constructs.

Production of ROS. To assess the molecular pathways leading to $\mathrm{CM}$ apoptosis activation, we determined the effects of $\mathrm{CM}$ on the formation of ROS. Renal cells were incubated in the presence of different CM concentrations (50, 100 , and $200 \mathrm{mgl} / \mathrm{ml}$ ) and ROS subsequently quantified. As shown in Figure 8a, both low-osmolar contrast media (LOCM) and iso-osmolar contrast media (IOCM) treatment induced a dose-response increase of ROS. This effect on ROS was significantly attenuated by NAC pre-treatment (Figure 8b).

\section{Discussion}

This study clearly demonstrates that (1) CM-induced epithelial tubular renal cells apoptosis represents a key mechanisms of $\mathrm{Cl}-\mathrm{AKI}$; (2) $\mathrm{CM}$ induces apoptotic cell death via three 

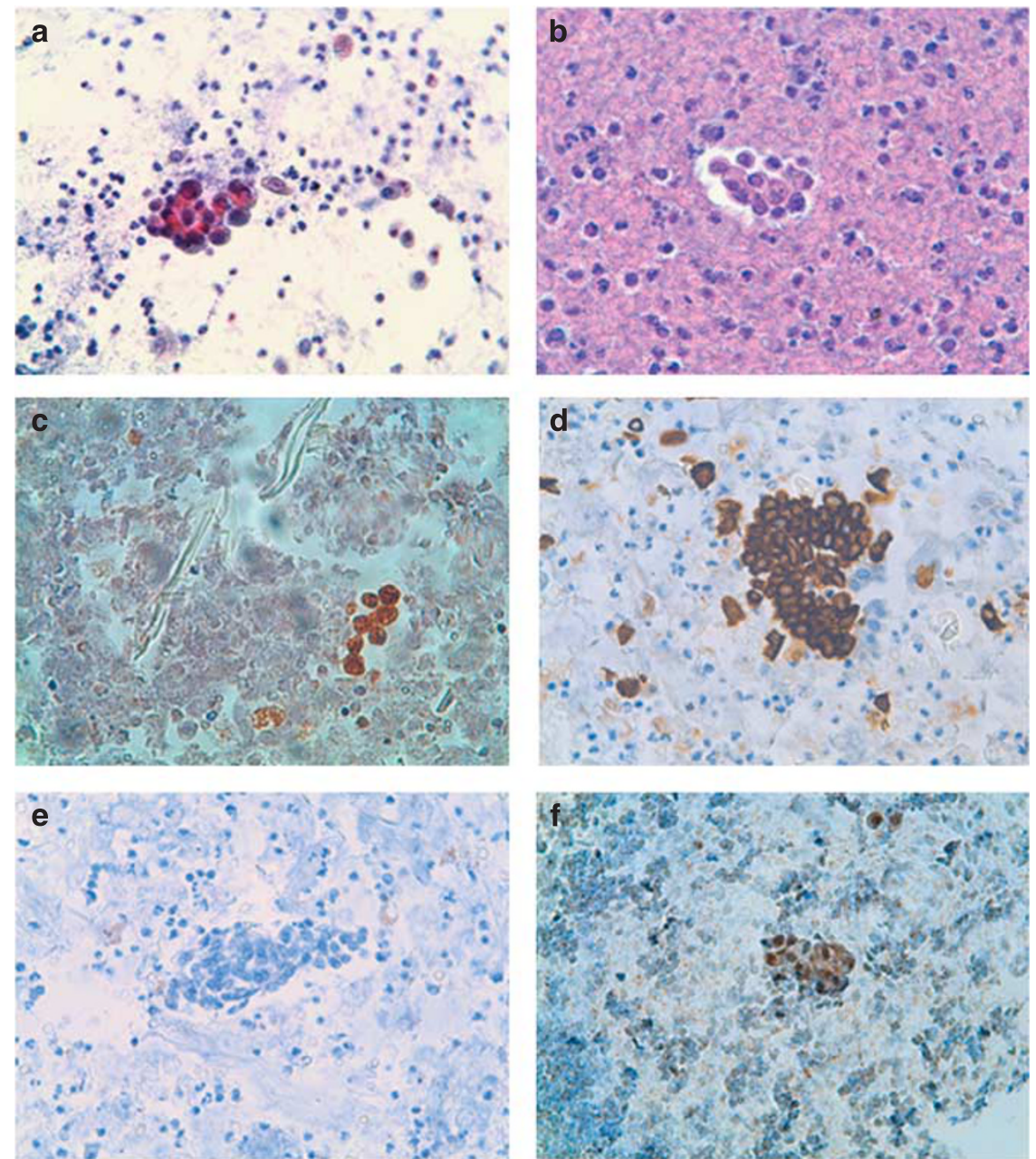

Figure 1 Immunohistochemistry of kidney tubular cells. (a) Cluster of tubular cells in an inflammatory background. The typical morphological features of tubular cells (regular elements with vacuolated and clear cytoplasm with eccentric nuclei) can be appreciated (Papanicolaou staining, $\times 400)$. (b) Urine cytological cell block preparation. This specimen type was used to perform specific tubular cell marker immunostaining. (Hematoxylin and eosin staining, $\times 400$ ). (c) The presence of tubular cells was confirmed by a specific staining for the Gal-3 marker. (Haematoxylin counterstained, $\times 400$ ). (d) The presence of distal tubular cells was confirmed by a specific staining for the CK7 marker. (Haematoxylin counterstained, $\times 400$ ). (e) Active caspase 3 staining of samples from untreated patient. (f) Active caspase 3 staining from samples of patients upon $48 \mathrm{~h}$ of $\mathrm{CM}$

important signaling pathways, namely, (a) ROS pathway, (b) stress kinase pathway, and (c) intrinsic apoptotic pathways, which are triggered by $\mathrm{CM}$ in this sequence; and (3) NAC and/or stress kinase inhibition may prevent the triggering of this cascade.

CM-induced apoptosis and Cl-AKI. This study demonstrated for the first time that the proposed in vitro apoptotic pathway inducing kidney damage was also appreciated in vivo. In vitro studies addressing the pathophysiology of $\mathrm{CM}$-induced apoptosis have been usually criticized because of the several limitations, including (1) the assessment of only one potential mechanism of the CM-induced renal cell damage in the absence of confounding variables that can be found in vivo (e.g., hypoxia due to hemodynamic changes or other systemic mechanisms); (2) the exposure to a constant concentration $\mathrm{CM}$ to all cells line, whereas in vivo, the more distal epithelial tubular cells are exposed to much higher concentration; (3) the potentially high dose of CM. Our in vivo demonstration of $\mathrm{CM}$-induced tubular renal cells apoptosis confirms the crucial role of this mechanism in the pathogenesis of $\mathrm{Cl}-\mathrm{AKI}$. Prophylactic strategies aimed to prevent contrast-induced renal cells apoptosis should be, therefore, investigated as novel therapeutic approaches to prevent $\mathrm{Cl}-\mathrm{AKI}$.

ROS pathway. In this study, we demonstrate that CM induces an increase in ROS production. This leads to eventual activation of the stress kinases JNK1/2 and p38 but not to ERK or PKC. It is well known that ROS can effectively activate stress kinases. ${ }^{19,20}$ Lee et al. ${ }^{21}$ recently reported that $\mathrm{CM}$ induce a time-dependent activation of JNK1/2. Our findings confirm and extend this observation. 

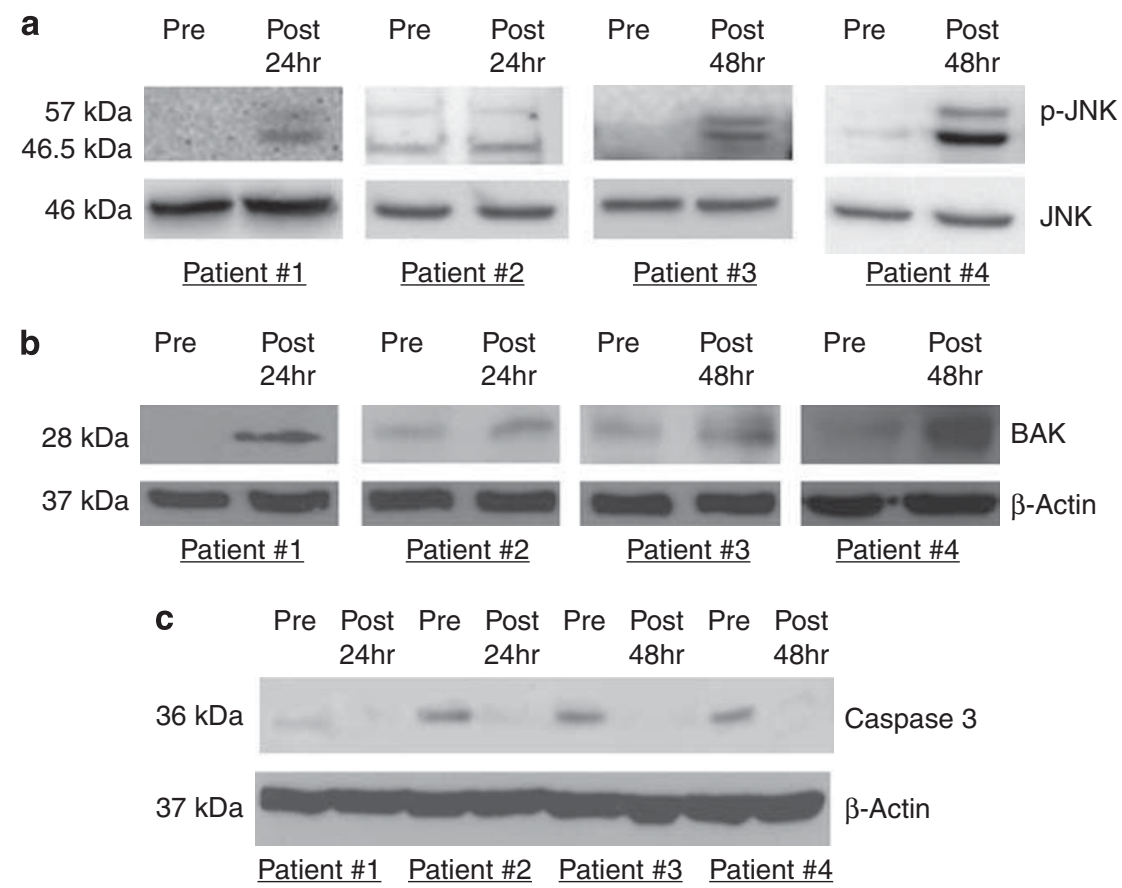

Figure 2 Effect of CM on renal cells in vivo. (a) JNK phosphorylation and BAK (b) expression levels were increased from epithelial tubular cells collected from 10 patients before and at 24 and $48 \mathrm{~h}$ after the contrast media exposure. (c) CM induced also an activation of caspase 3 . Representative of four patients was shown
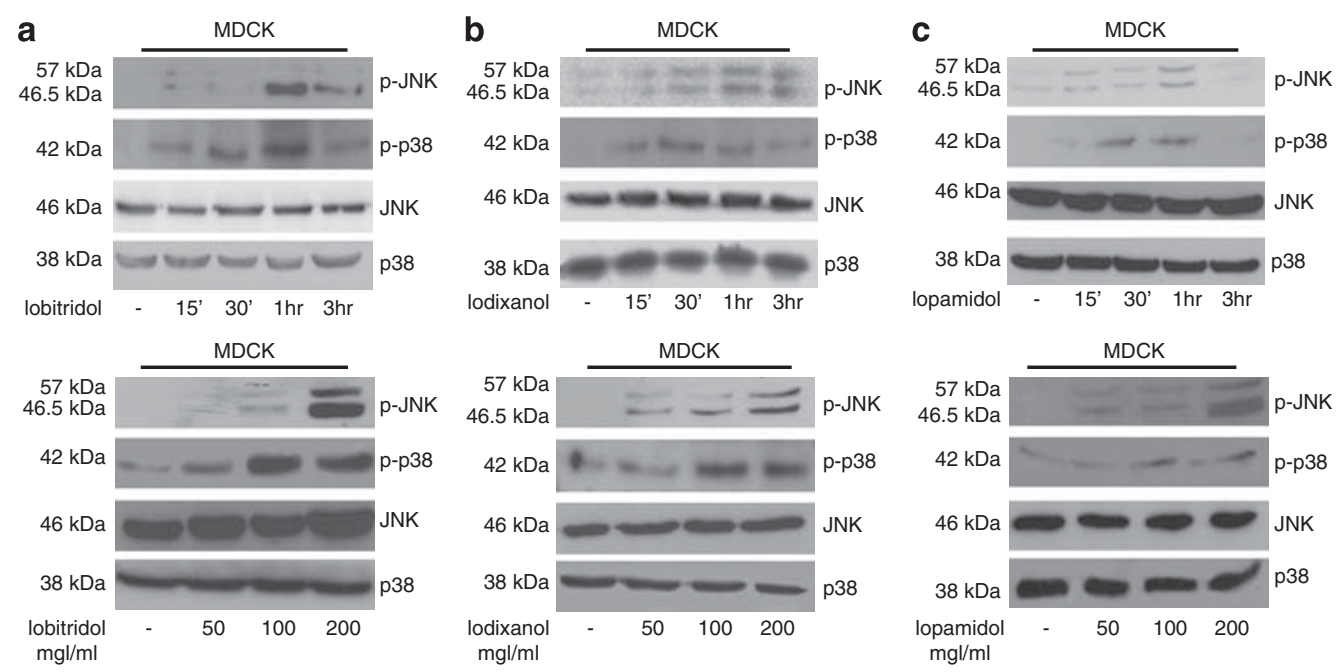

Figure 3 Activation of JNK and p38 after contrast media exposure. Dose-response and time-course of JNK and p38 activation induced by treatment of MDCK cells with iobitridol (a), iodixanol (b), and iopamidol (c). Cell extracts were analyzed by western blot for phospho-JNK, phospho-p38, JNK expression, and p38 expression

This study indeed clarifies that ROS induce stress kinases activation following $\mathrm{CM}$ incubation. The observation that ROS activation is dose- and time-dependent underscores two important aspects of contrast-induced kidney damage well known both in experimental ${ }^{4}$ and clinical ${ }^{22}$ models.

Stress kinases pathway. Our study demonstrates that CM induces renal cell apoptosis by the activation of the JNK $1 / 2$ and the p38 pathways (but not ERK and PKC) via an upregulation of the intracellular levels of ROS. JNK1/2, p38, and ERK are well-characterized subgroups of a large MAPK family. Although the ERK pathway is most commonly linked to the regulation of cell proliferation, the JNK $1 / 2$ and p38 pathways are primarily activated by various types of environmental stress: osmotic shock, UV irradiation, oxidative stress, protein synthesis inhibitors, and proinflammatory cytokines. ${ }^{23}$ Therefore, JNK1/2 and p38 are often grouped together and are referred as stressactivated protein kinases (SAPKs). ERK, JNK1/2, and p38 have all been shown to be activated in response to the 
a

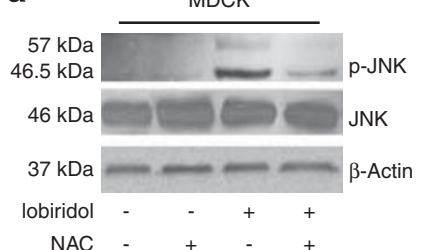

b

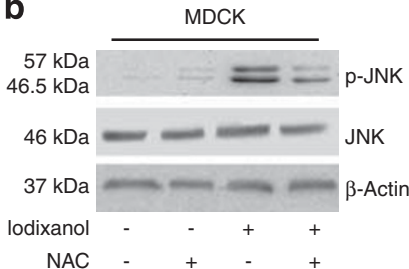

C

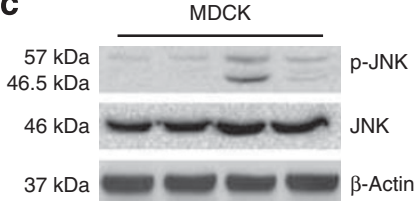

lopamidol NAC

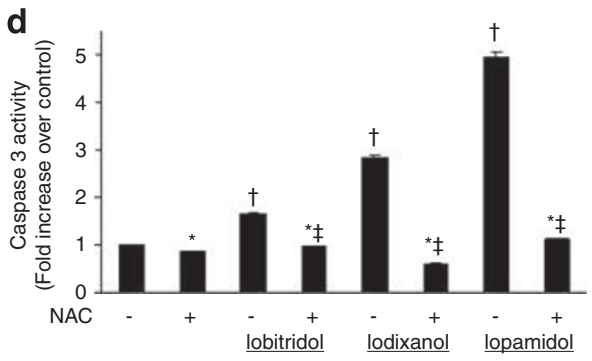

Figure 4 NAC effects on JNK activation and on apoptosis in renal cells. Western blot of the effects of NAC pretreatment on JNK activation by iobitridol (a), iodixanol (b), and iopamidol (c). (d) Caspase 3 assay in renal cells incubated with contrast media and pretreated with NAC. ${ }^{\star} P>0.05$ versus control; ${ }^{\dagger} P<0.030$ versus control; ${ }^{\ddagger} P<0.005$ versus column without NAC
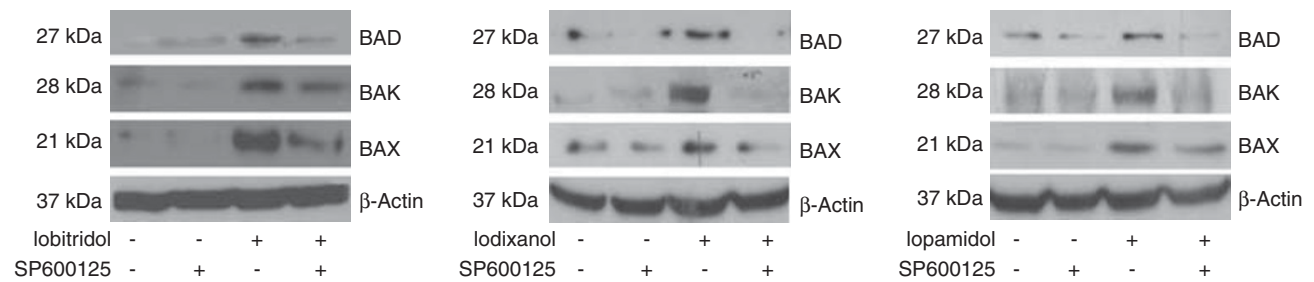

Figure 5 Effect of CM-induced stress kinases activation on Bcl2 pro-apoptotic family members. CM induced an increase of pro-apoptotic family members BAX, BAD, and BAK that was reverted by the pre-treatment with SP 600125
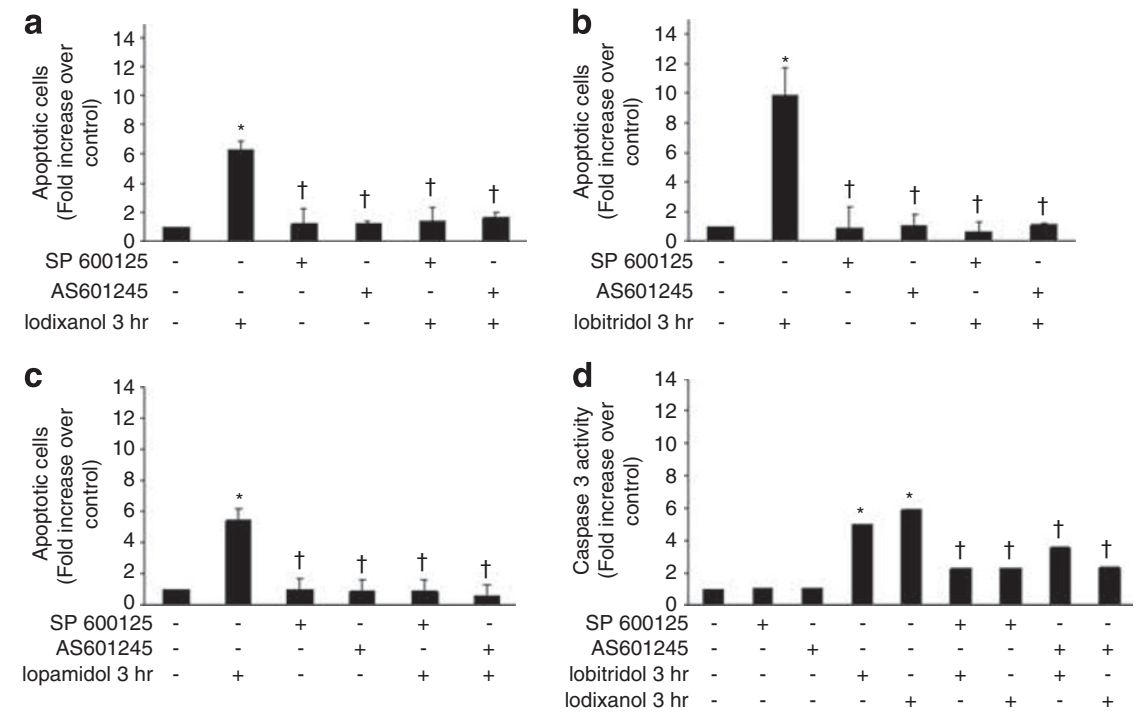

Figure 6 Effects of JNK inhibitors on renal cells apoptosis. SP600125 and AS601245 strongly reduced iodixanol (a), iobitridol (b), and iopamidol (c) induced renal cell apoptosis evaluated by annexin V staining. (d) Caspase 3 assay in renal cells incubated with contrast media and pretreated with SP600125 and AS601245. ${ }^{*} P<0.001$ versus control; ${ }^{\dagger} P>0.05$ versus control 


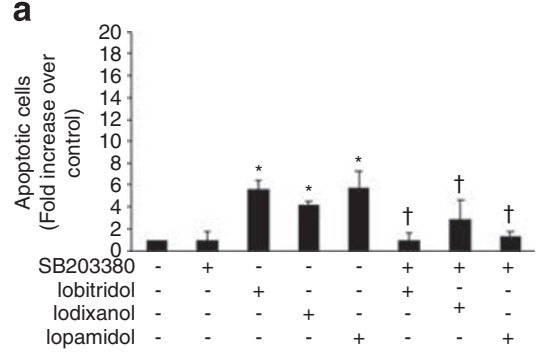

C

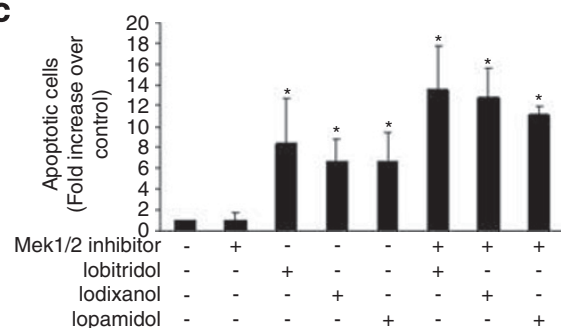

b

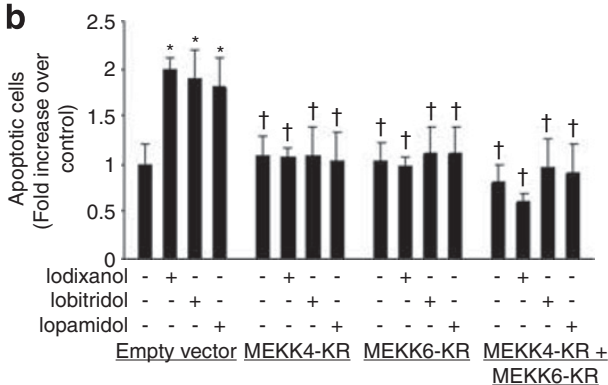

d

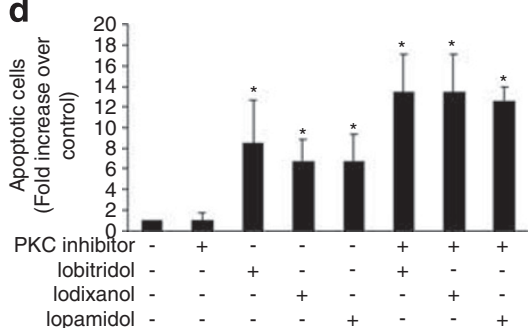

Figure 7 Effects of p38, MAPK, and PKC inhibitors on renal cells apoptosis. P38 inhibitor, SB203580 (a) or MKK4-KR, and MEKK6-KR transfection reduced contrast media induced apoptosis (b). However, MEK1/2 inhibitor (c) and PKC inhibitor (d) did not impact iobitridol-, iodixanol-, and iopamidol-induced renal cell apoptosis evaluated by annexin $V$ staining. ${ }^{*} P<0.001$ versus control; ${ }^{\dagger} P>0.05$ versus control
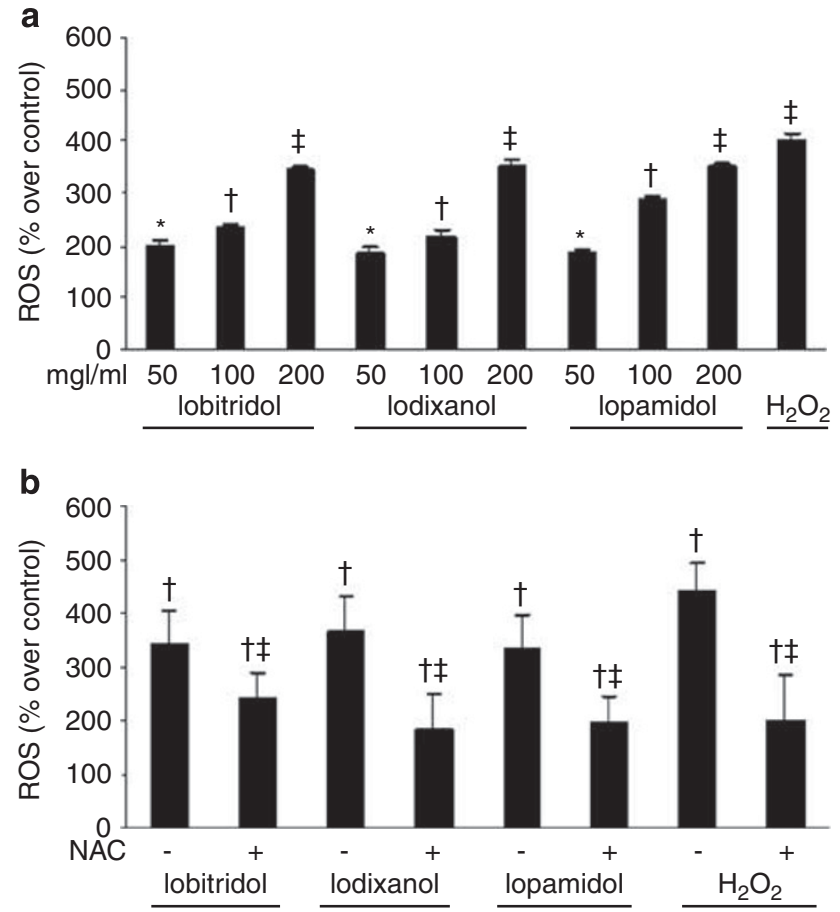

Figure 8 Production of reactive oxygen species (ROS) after contrast media treatment. MDCK cells were treated for $3 \mathrm{~h}$ with 50,100 or $200 \mathrm{mgl} / \mathrm{ml}$ of iodixanol, iobitridol, iopamidol, and with $400 \mu \mathrm{M}$ of $\mathrm{H}_{2} \mathrm{O}_{2}$ (positive control). (a) ROS formation on different CM. By ANCOVA test, ROS production was significantly increased in the presence of medium $(100 \mathrm{mgl} / \mathrm{ml})$ and high $(200 \mathrm{mg} / \mathrm{ml})$, but not at low $(50 \mathrm{mgl} /$ $\mathrm{ml}$ ) dose of contrast media. ${ }^{*} P>0.05$ versus control; ${ }^{\dagger} P<0.030$ versus control; ${ }^{\ddagger} P<0.001$ versus control. (b) Effects of $2 \mathrm{~h}$ NAC $(100 \mathrm{mM})$ pretreatment on ROS formation following contrast media exposure. ${ }^{\dagger} P<0.001$ versus control; ${ }^{\ddagger} P<0.006$ versus column without NAC

intracellular redox state and oxidative stress, and potentially contribute to influencing cell survival or cell death. ERK and JNK/p38 have opposing functions, whereas ERK are generally pro-survival and SAPKs pro-apoptotic. The modification of MAPK signal transduction pathway by ROS generates a great variety of biological responses. JNK1/2 phosphorylate and release two $\mathrm{Bcl}-2$-related proteins that are normally sequestered within the cell. ${ }^{20,24}$ The release of these key proteins can directly activate Bax by causing dissociation from its cytoplasmic anchor. Bax is then free to translocate to the mitochondria, where it undergoes oligomerization and initiates the release of cytochrome $c$ and other pro-death mediators into the cytosol. JNK1/2 are also capable to enhanced Bax-to Bcl2 expression ratio, loss of mitochondrial membrane potential cytochrome $c$ release, and caspase cascade reaction. ${ }^{25}$ Our data confirm previous findings, demonstrating that $\mathrm{CM}$ are able to induce an increase of some of the Bcl2-family pro-apoptotic members (BAD, BAK, and BAX), and that JNK1/2 inhibitor was able to prevent this effect.

Intrinsic apoptotic pathway. Previous studies demonstrated that $\mathrm{CM}$ induces renal cells apoptosis through the activation of the intrinsic or mitochondrial pathway. ${ }^{4}$ In this study, we clarify that this effect is triggered by stress kinases JNK1/2 and p38 activation. Indeed we observed that pre-treatment with JNK1/2 and p38 inhibitors prevent (1) CM-induced increase of the Bcl2-family pro-apoptotic members (BAD, BAK, and BAX), and (2) CM-mediated caspase 3 activation. These effects act in concert to attenuate $\mathrm{CM}$-induced renal cell apoptosis. The essential role of $\mathrm{JNK} 1 / 2$ during the apoptotic process of $\mathrm{CM}$ confirms that $\mathrm{CM}$ uses the intrinsic apoptotic signaling rather than the extrinsic or death receptor pathway. The intrinsic or mitochondrial pathway was originally identified as the main mediator of apoptosis signals initiated by stress or toxic stimuli. The major participants in this kinase cascade are two members of the MAPKs, JNK1/2, and p38MAP kinase, as well as their upstream kinases such as MKKs. ${ }^{17}$ 
Potential strategies for preventing $\mathrm{CM}$-induced renal cell apoptosis. In this study, we demonstrated that strategies inhibiting the CM-signaling pathways may prevent renal cell apoptosis. In particular, we tested two approaches inducing an upstream (NAC) or a downstream (JNK1/2 and p38 inhibitors) CM signaling pathway blockage. The positive results obtained by both these approaches represent a further confirmation of our proposed CM signaling pathway (Figure 8). We have already demonstrated that NAC pretreatment is capable to prevent apoptosis in renal cells. ${ }^{4,26}$ In this study, we observed that NAC prevents CM-induced ROS production and therefore inhibits JNK1/2 and p38 activation as well as apoptosis, suggesting the existence of a specific target for NAC upstream to the apoptosis-executing stress kinases in the CM-activated signaling pathway. Indeed, the increase of intracellular ROS by $\mathrm{CM}$ and/or $\mathrm{H}_{2} \mathrm{O}_{2}$ was almost completely abolished by NAC.

Study limitations. Additional data are necessary to address the issue of which CM component and chemical properties (such as viscosity) cause ROS production. The investigators who evaluated the cells damage were not blinded to the $\mathrm{CM}$ and the protective strategy attempted. We did not use proximal tubular cells. We selected Madin-Darby canine kidney (MDCK) cells for two reasons: (1) distal tubular cells are more affected by CM damage, and (2) handling of the MDCK cells is easier than other kidney cell lines (such as, porcine proximal renal tubular LLC-PK1).

Conclusions. In this work, we were able to demonstrate that $\mathrm{CM}$ induces apoptotic cell death via three important signaling pathways, (a) ROS pathway, (b) JNK/p38 pathway, and (c) intrinsic apoptosis pathway, which are triggered by $\mathrm{CM}$ in this sequence. The relationship between these three sequential pathways was strongly suggested and supports novel therapeutic approaches to prevent Cl-AKI.

\section{Patients and Methods}

Patients' population and urine cells collection. The urine of patients with chronic kidney disease (CKD) who experienced contrast-induced AKI (Cl-AKI) were collected the day before and through the 24 and $48 \mathrm{~h}$ following $\mathrm{CM}$ exposure. CKD was defined as an estimated glomerular filtration rate $<60 \mathrm{ml} / \mathrm{min}$ per $1.73 \mathrm{~m}^{2}$, calculated by applying the Levey-modified Modification of Diet in renal Disease formula: $\left(186.3 \times\right.$ serum creatinine-1.154) $\times($ age-0.203 $) \times(0.742$ if female $) .{ }^{27}$ $\mathrm{Cl}-\mathrm{AKI}$ was defined as an increase in the serum creatinine concentration, $\geq 0.3 \mathrm{mg}$ $\mathrm{dl}$, from the baseline value at $48 \mathrm{~h}$ after $\mathrm{CM}$ administration or the need for dialysis (Crit Care 2007;11:R31). In all instances the iodixanol (Visipaque, $320 \mathrm{mg}$ iodine/ml, GE Healthcare Europe, Buckinghamshire, UK), a non-ionic, iso-osmolar CM was used. Exfoliated cell pellets from the urine of the patients were collected by centrifugation at 1200 r.p.m. for $25 \mathrm{~min}$. A fraction of urine samples was sent to the pathologist for cytological analysis and a fraction to the laboratory for in vitro assay. All samples were stored at $-80^{\circ} \mathrm{C}$ for a maximum of 2 months.

The presence of tubular cells was assessed by using morphological and immunocytochemical criteria. The former were evaluated on cytospin preparations stained by standard Papanicolaou staining method; the latter were assessed by immunostaining for the Gal-3, CK7 tubular cell markers, and active caspase 3. To this end, cell block preparations were used. To ensure their adequacy, cell blocks were stained with hematoxylin and eosin. CK7 was immunostained by mouse monoclonal antibody (clone OV-TL12/30; Dako, Milano, Italy); the caspase 3 expression was detected by rabbit polyclonal antibody (Cell Signaling 9661, Cell Signaling, Danvers, MA, USA). For CK7 and caspase 3, signal was developed by the polyvalent LSAB-peroxidase Dako Kit (Dako). As far as, Gal 3 staining is concerned, the galectin 3 tyrotest (Biocare Medical, Concord, CA, USA) was used as previously described. ${ }^{28}$ To extract protein from exfoliated cells, the pellet obtained on centrifugation was resuspended in ice-cold TRAP buffer (tris(idrossimetil)amminometano cloridrato (ph 7.5) $10 \mathrm{mM}, \mathrm{MgCl}_{2} 1 \mathrm{mM}$, ethylene glycol tetraacetic acid (EGTA) $1 \mathrm{mM}$, phenyl methylsulfonyl $0.1 \mathrm{mM}, \beta$-mercaptoethanol $5 \mathrm{mM}$, CHAPS $0.5 \%$, and glycerol $10 \%$ ) and incubated on ice for $1 \mathrm{~h}$. The lysate was centrifuged for $20 \mathrm{~min}$ a 13.200 r.p.m. at $4^{\circ} \mathrm{C}$. The supernatant was collected.

Culture conditions and reagents. Canine Madin-Darby proximal renal tubular (MDCK) cells were grown in a $5 \% \mathrm{CO}_{2}$ atmosphere in Dulbecco's modified Eagle's medium containing $10 \%$ heat-inactivated fetal bovine serum, $2 \mathrm{mM}$ L-glutamine and $100 \mathrm{U} / \mathrm{ml}$ penicillin-streptomycin. Cells were routinely passaged when $80-85 \%$ confluent. Media, sera, and antibiotics for cell culture were from Life Technologies Inc. (Grand Island, NY, USA). Protein electrophoresis reagents were from Bio-Rad (Richmond, VA, USA) and western blotting and ECL reagents (GE Healthcare). PKC inhibitor Ro-32-0432 was from Calbiochem (Gibbstown, NJ, USA) and LY294002 was from Cell Signaling). JNK inhibitors AS601245 and SP 60125 were, respectively, from Alexis (Florence, Italy) and Sigma (St. Louis, MO, USA). P38 inhibitor, SB203380, and MEK1/2 inhibitor, V0126 were from Calbiochem. All other chemicals were from Sigma. The following antibodies were used for immunoblotting: anti- $\beta$ actin (Sigma), anti-P-JNK and P-p38, p38 (Cell Signaling), anti-JNK (BD Bioscience, Franklin Lakes, NJ, USA), BAK and BAD were from Santa Cruz Biotechnology (Santa Cruz, CA, USA), BAX was from BD Bioscience.

Contrast media. Several CM were tested: (1) iodixanol (Visipaque, $320 \mathrm{mg}$ iodine $/ \mathrm{ml}$, GE Healthcare, Europe) non-ionic, IOCM (290 mOsm $/ \mathrm{kg}$ of water); (2) iobitridol (Xenetix, $250 \mathrm{mg}$ iodine/ml, Guerbet, Roissy CDG, France) non-ionic, LOCM ( $915 \mathrm{mOsm} / \mathrm{kg}$ of water); (3) iopamidol (lomeron, $350 \mathrm{mg}$ iodine/ml, Bracco, Milano, Italy) non ionic, LOCM (796 mOsm/ $/ \mathrm{kg}$ of water).

Cell transfection. To inhibit $\mathrm{p} 38$ or JNK $1 / 2$ activation, we transfected the cells, respectively, with the kinase-dead mutant of the upstream p38 kinase, MKK6 (pCEFL GST MKK6-KR), or with the kinase-dead mutant of the upstream JNK1/2 kinase, MKK4-KR (pcDNA3 MKK4-KR) MDCK cells were cultured to $80 \%$ confluence, kept in antibiotic-free, serum-containing medium, and transiently transfected using Lipofectamine and Plus Reagent (Invitrogen, Milano, Italy) with $5 \mu \mathrm{g}$ of MKK4-KR, MKK6-KR cDNAs or with control vector, as indicated. CDNA plasmids were a kind gift of Dr. Mario Chiariello (Siena, Italy).

ROS determination. Formation of ROS was detected by the signal obtained from the fluorescent reaction products dichlorofluorescein and BODIPY, a fluorescent ratio probe for indexing peroxidation in membranes ${ }^{29}$ by the use of flow cytometry (FACSCalibur, BD Bioscience; Perkin Elmer; Waltham, MA, USA; Cell Quest software, BD Bioscience). ROS production was evaluated upon 50, 100, or $200 \mathrm{mgl} / \mathrm{ml}$.

To assess the effects of NAC on ROS production, MDCK cells were pretreated for $2 \mathrm{~h}$ with NAC $(100 \mathrm{mM})$, incubated with BODIPY for $45 \mathrm{~min}$ and then exposed to CM. ROS formation was valuated after $2 \mathrm{~h}$ of $\mathrm{CM}$ exposure.

Stress kinases. To address whether the ROS production induces an activation of stress kinases, MDCK cells were treated at different times and different doses of CM $(50,100$, or $200 \mathrm{mgl} / \mathrm{ml}$; with all the tested CM at the same dose reported above. JNK and p38 phosphorylation (activation) was assessed with western blot with specific anti-P-JNK or anti-P-38 antibodies (Cell Signaling), as described. ${ }^{30}$ To investigate whether inhibition of JNK1/2 was capable to prevent cell death, renal cells were overnight pre-treated with $40 \mu \mathrm{M}$ of JNK1/2 inhibitors SP600125 or AS601245 and then exposed to CM for a short $(30 \mathrm{~min})$ or a longer $(3 \mathrm{~h})$ period. Similarly, inhibitors of other signaling pathways were used: MEK $1 / 2$ inhibitor V0126 (10 $\mu \mathrm{M}$ incubated over night), PKC inhibitor (212 $\mu \mathrm{M}$ incubated over night) and p38 inhibitor, SB203580 (10 $\mu \mathrm{M}$ incubated overnight). The doses and the incubation time of drug inhibitors used have been choose in order of not causing any nonspecific effects on other signaling pathways. Furthermore, in order of reinforce the role of JNK activation on CM-induced apoptosis, we used two different JNK inhibitors (SP600125 and AS601245).

Caspase assay. The assay was performed using the Colorimetric CaspACE Assay System, (Promega, Madison, WI, USA) as reported by instruction manual. Briefly, MDCK cells were pre-treated with NAC $(100 \mathrm{mM})$ and then treated for $3 \mathrm{~h}$ with iodixanol, iobitridol, and iopamidol. Cells were harvest in caspase assay buffer, and proteins were quantified by Bradford assay. Total protein used was $50 \mu \mathrm{g}$. 
Protein isolation and western blotting. Cellular pellets were washed twice with cold phosphate-buffered saline (PBS) and resuspended in JS buffer (Hepes $50 \mathrm{mM}, \mathrm{NaCl} 150 \mathrm{nM}, 1 \%$ glycerol, $1 \%$ Triton X100, $1.5 \mathrm{mM} \mathrm{MgCl}$, and $5 \mathrm{mM}$ EGTA) containing Proteinase Inhibitor Cocktail (Roche, Milano, Italy). Solubilized proteins were incubated for $1 \mathrm{~h}$ on ice. After centrifugation at 13200 r.p.m. for $10 \mathrm{~min}$ at $4^{\circ} \mathrm{C}$, lysates were collected as supernatants. Sample extract $(80 \mu \mathrm{g})$ were resolved on a $12 \%$ SDS-polyacrylamide gel using a mini-gel apparatus (Bio-Rad Laboratories) and transferred to Hybond-C extra nitrocellulose (GE Healthcare Europe). Membrane was blocked for $1 \mathrm{~h}$ with $5 \%$ non-fat dry milk in TBS containing $0.05 \%$ Tween-20 and incubated over night at $4^{\circ} \mathrm{C}$ with specific antibodies. Indicated antibodies were used for the immunoblotting. Washed filters were then incubated for $45 \mathrm{~min}$ with horseradish peroxidase-conjugated anti-rabbit or anti-mouse secondary antibodies (GE Healthcare Europe) and visualized using chemioluminescence detection (GE Healthcare Europe).

Cell death quantification. Cells were plated in 96-well plates in triplicate, stimulated and incubated at $37^{\circ} \mathrm{C}$ in a $5 \% \mathrm{CO}_{2}$ incubator. lobitridol, iodixanol, iopamidol, iohexol, and NAC were used in vitro at doses and time indicated. Apoptosis was analyzed via propidium iodide incorporation in permeabilized cells by flow cytometry as previously described. ${ }^{31}$ Briefly, the cells $\left(2 \times 10^{5}\right)$ were washed in PBS and resuspended in $200 \mu \mathrm{l}$ of a solution containing $0.1 \%$ sodium citrate, $0.1 \%$ Triton X-100, and $50 \mu \mathrm{g} / \mathrm{ml}$ propidium iodide (Sigma). Following incubation at $4{ }^{\circ} \mathrm{C}$ for $30 \mathrm{~min}$ in the dark, nuclei were analyzed with a Becton Dickinson FACScan flow cytometer (BD Bioscience). Cellular debris was excluded from analyses by raising the forward scatter threshold, and the DNA content of the nuclei was registered on a logarithmic scale. The percentage of elements in the hypodiploid region was calculated.

Statistical analysis. Continuous variables are given as mean \pm 1 S.D. or median and interquartile ranges, when appropriate. Categorical variables were reported as percentage. Continuous variables in the groups were analyzed by oneway analysis of variance test. The level of statistical significance was $<0.05$. Multiplicity issues were addressed using the Bonferroni adjustment. Data were analyzed with SPSS 13.0 (SPSS Inc., Chicago, IL, USA) for Windows.

\section{Conflict of interest}

The authors declare no conflict of interest.

Acknowledgements. This work was partially supported by funds from the AIRC (Associazione Italiana Ricerca sul Cancro) (No 10620 to GC) and Fondazione SDN. CQ is recipient of FIRC (Associazione Italiana Ricerca sul Cancro) fellowship.

1. Andersen KJ, Christensen El, Vik H. Effects of iodinated X-ray contrast media on renal epithelial cells in culture. Invest Radiol 1994; 29: 955-962.

2. Humes HD, Hunt DA, White MD. Direct toxic effect of the radiocontrast agent diatrizoate on renal proximal tubule cells. Am J Physiol 1987; 252: F246-F255.

3. Messana JM, Cieslinski DA, Nguyen VD, Humes HD. Comparison of the toxicity of the radiocontrast agents, iopamidol and diatrizoate, to rabbit renal proximal tubule cells in vitro. J Pharmacol Exp Ther 1988; 244: 1139-1144.

4. Romano G, Briguori C, Quintavalle C, Zanca C, Rivera NV, Colombo A et al. Contrast agents and renal cell apoptosis. Eur Hearth J 2008; 29: 2569-2576.

5. Hengartner MO. The biochemistry of apoptosis. Nature 2000; 407: 770-776.

6. Okada H, Mak TW. Pathways of apoptotic and non-apoptotic death in tumour cells. Nat Rev Cancer 2004; 4: 592-603.

7. Ghobrial IM, Witzig TE, Adjei AA. Targeting apoptosis pathways in cancer therapy. CA Cancer J Clin 2005; 55: 178-194.

8. Katholi RE, Woods WTJ, Taylor GJ, Deitrick CL, Womack KA, Katholi CR et al. Oxygen free radicals and contrast nephropathy. Am J Kidney Dis 1998; 32: 64-71.

9. Drager LF, Andrade L, Barros de Toledo JF, Laurindo FR, Machado César LA, Seguro AC Renal effects of $\mathrm{N}$-acetylcysteine in patients at risk for contrast nephropathy: decrease in oxidant stress-mediated renal tubular injury. Nephrol Dial Transplant 2004; 19: 1803-1807.

10. Zager RA, Johnson AC, Hanson SY. Radiographic contrast media-induced tubular injury: evaluation of oxidant stress and plasma membrane integrity. Kidney Int 2003; 64: 128-139.

11. Bakris GL, Lass N, Gaber AO, Jones JD, Burnett JCJ. Radiocontrast medium-induced declines in renal function: a role for oxygen free radicals. Am J Physiol 1990; 258: F115-F120.

12. Bakris GL, Gaber AO, Jones JD. Oxygen free radical involvement in urinary Tamm-Horsfall protein excretion after intrarenal injection of contrast medium. Radiology 1990; 175: 57-60.

13. Matsuzawa A, Ichijo H. Redox control of cell fate by MAP kinase: physiological roles of ASK1-MAP kinase pathway in stress signaling. Biochim Biophys Acta 2008; 1780: 1325-1336.

14. Heyman SN, Rosen S, Khamaisi M, Idée JM, Rosenberger C. Reactive oxygen species and the pathogenesis of radiocontrast-induced nephropathy. Invest Radiol 2010; 45: 188-195.

15. Robinson MJ, Cobb MH. Mitogen-activated protein kinase pathways. Curr Opin Cell Biol 1997; 9: 180-186.

16. Kyriakis JM, Banerjee P, Nikolakaki E, Dai T, Rubie EA, Ahmad MF et al. The stressactivated protein kinase subfamily of c-Jun kinases. Nature 1994; 369: 156-160.

17. Ichijo H. From receptors to stress-activated MAP kinases. Oncogene 1999; 18: 6087-6093.

18. Ip YT, Davis RJ. Signal transduction by the c-Jun N-terminal kinase (JNK)-from inflammation to development. Curr Opin Cell Biol 1998; 10: 205-219.

19. Kyriakis JM, Avruch J. Mammalian mitogen-activated protein kinase signal transduction pathways activated by stress and inflammation. Physiol Rev 2001; 81: 807-869.

20. Lei K, Davis RJ. JNK phosphorylation of Bim-related members of the Bcl2 family induces Bax-dependent apoptosis. Proc Natl Acad Sci USA 2003; 100: 2432-2437.

21. Lee HC, Sheu SH, Yen HW, Lai WT, Chang JG. JNK/ATF2 pathway is involved in iodinated contrast media-induced apoptosis. Am J Nephrol 2009; 31: 125-133.

22. Marenzi G, Assanelli E, Campodonico J, Lauri G, Marana I, De Metrio M et al. Contrast volume during primary percutaneous coronary intervention and subsequent contrastinduced nephropathy and mortality. Ann Intern Med 2009; 150: 170-177.

23. Matsuzawa A, Ichijo H. Redox control of cell fate by MAP kinase: physiological roles of ASK1-MAP kinase pathway in stress signaling. Biochim Biophys Acta 2008; 1780: 1325-1336.

24. Parinandi NL, Kleinberg MA, Usatyuk PV, Cummings RJ, Pennathur A, Cardounel AJ et al. Hyperoxia-induced NAD(P)H oxidase activation and regulation by MAP kinases in human lung endothelial cells. Am J Physiol Lung Cell Mol Physiol 2003; 284: L26-L38.

25. Cao XH, Wang AH, Wang CL, Mao DZ, Lu MF, Cui YQ et al. Surfactin induces apoptosis in human breast cancer MCF-7 cells through a ROS/JNK-mediated mitochondrial/caspase pathway. Chem Biol Interact 2010; 183: 357-362

26. Briguori C, Quintavalle C, De Micco F, Condorelli G. Nephrotoxicity of contrast media and protective effects of acetylcysteine. Arch Toxicol 2011; 85: 165-173.

27. Foundation NK. K/DOQI clinical practice guidelines for chronic kidney disease: evaluation, classification, and stratification. Am J Kidney Dis 2002; 39: S1-S266.

28. Bartolazzi A, Orlandi F, Saggiorato E, Volante M, Arecco F, Rossetto R et al. Galectin-3expression analysis in the surgical selection of follicular thyroid nodules with indeterminate fine-needle aspiration cytology: a prospective multicentre study. Lancet Oncol 2008; 9: 543-549.

29. Drummen GP, van Liebergen LC, Op den Kamp JA, Post JA C11-BODIPY(581/591), an oxidation-sensitive fluorescent lipid peroxidation probe: (micro)spectroscopic characterization and validation of methodology. Free Radic Biol Med 2002; 33: 473-490.

30. Condorelli G, Trencia A, Vigliotta G, Perfetti A, Goglia U, Cassese A et al. Multiple members of the mitogen-activated protein kinase family are necessary for PED/PEA-15 anti-apoptotic function. J Biol Chem 2002; 277: 11013-11018.

31. Garofalo M, Romano G, Quintavalle C, Romano MF, Chiurazzi F, Zanca C et al. Selective inhibition of PED protein expression sensitizes B-cell chronic lymphocytic leukaemia cells to TRAIL-induced apoptosis. Int J Cancer 2007; 120: 1215-1222.
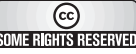

Cell Death and Disease is an open-access journal published by Nature Publishing Group. This work is licensed under the Creative Commons Attribution-Noncommercial-No Derivative Works 3.0 Unported License. To view a copy of this license, visit http://creativecommons.org/licenses/by-nc-nd/3.0/ 